\title{
Research on Effective Teaching Strategies of Basketball General Course for Physical Education Majors in Colleges and Universities in China
}

\author{
Songhe Xin \\ College of P.E. Science, Lingnan Normal University, Zhanjiang, 524048, Guangdong Province, China
}

\begin{abstract}
Through the methods of literature review, expert interview and field investigation, this paper analyzes the effective teaching and promotion strategies of basketball general course for physical education major in Colleges and universities in China. It is believed that the main problems in the effective teaching of basketball general course of physical education major in China are cognitive bias in effective teaching, ignoring the effectiveness of teaching process, and dissimilation of effective teaching orientation In the problem, this paper puts forward the specific strategies to improve the effective teaching of general basketball course of physical education major in Colleges and universities, that is to correctly understand the effective teaching, pay attention to the effective teaching process, and establish the effective teaching goal orientation, so as to provide enlightenment for peer researchers to explore effective teaching together, and provide reference for peer workers to better understand effective teaching and improve effective teaching efficiency.
\end{abstract}

Keywords: Physical education major, Basketball general course, Effective teaching.

\section{Introduction}

With socialism of Chinese characteristics entering a new era, the party and the state have made a decision to develop the new normal education. To develop the new normal education, it is necessary to pay more attention to the implementation of the fundamental task of moral education, to pay more attention to higher level, more systematic, more intelligent and more open education, and to form a new goal, new form and new mode of normal education. From the perspective of new normal education deployment, the new era puts forward higher requirements for personnel training. Therefore, in order to better train qualified new normal education personnel for the country, it is necessary to timely adjust the existing personnel training objectives and teaching process of normal schools. As an important part of the new normal education, physical education major in Colleges and universities of our country must effectively adjust the existing talent training mode and teaching process in order to cultivate qualified talents who better meet the requirements of the new normal education. In view of the current college physical education professional basketball class teaching process in accordance with the old traditional teaching routine or even "sheep" and other inefficient teaching phenomenon, this paper puts forward the effective teaching concept. The core of effective teaching is to care about the efficiency of classroom teaching, that is, to pay attention to "what kind of teaching is effective?", "What kind of teaching is efficient", "What kind of teaching is inefficient or ineffective?", "How to improve the efficiency of classroom teaching". The concept of effective teaching originated from the scientific movement of teaching in the West in the first half of the 20th century, and has already attracted the attention of educators all over the world. Rajindra Kunwar stated the problems in the effective teaching of mathematics in basic education in Nepal, and put forward how to solve them effectively [1]; Hans Teke discusses how to improve the effective teaching of moral education with different modes; Wei Hong and others summarized the basic characteristics of effective teaching in Colleges and universities in China [3]; Wang Xi made a comparative study on the differences of different classroom behaviors between effective teaching and inefficient Teaching [4]; Wang Shuwei studied the effectiveness of physical education classroom teaching in senior high schools in Lanzhou [5]. But so far, the effective teaching of basketball general course of physical education major in Colleges and universities has not attracted scholars' attention. Therefore, under the background that the party and the state put forward the development of new normal education and asked to cultivate more qualified normal students in the new era, it is necessary to strengthen the effective teaching research of basketball general course of physical education major in Colleges and universities. Based on this, this paper analyzes the problems existing in the effective teaching of basketball general course of physical education major in Colleges and universities, and puts forward specific strategies to improve the effective teaching of basketball general course of physical education major in Colleges and universities, in order to provide reference for peer researchers and workers to explore effective teaching.

\section{The Basic Connotation of Effective Teaching}

On the connotation of effective teaching, different scholars at home and abroad have different views. At present, many scholars have defined effective teaching. In his monograph effective teaching in school, foreign scholar Kiriaco believes that effective teaching refers to the use of certain educational activities to guide students to learn more efficiently [6]; Baluntai and others believe that effective teaching refers to the effective realization of teaching objectives, that is, students are willing to learn and can engage in learning after teaching that they can not engage in before teaching [7]. Zhang Lu, a domestic scholar, believes that effective teaching refers to the teaching that brings the best teaching effect within a certain amount of teaching investment (time, energy and effort); Yao Limin believes that effective teaching refers to the teaching that teachers follow the objective law 
of teaching activities in teaching, achieve as much teaching effect as possible with as little teaching investment as possible, so as to achieve specific teaching objectives [9]. Through the analysis of scholars' definition of effective teaching, it can be seen that scholars emphasize the efficiency of teaching in defining effective teaching, that is, they emphasize the efficiency of teachers' teaching and the learning effect of students. From the perspective of teachers' teaching efficiency, effective teaching is the effectiveness of teachers' teaching process, which not only reflects that the teaching process conforms to the teaching rules, such as reasonable teaching preparation activities, preparing suitable teaching objectives, forming practical teaching plans, etc; It can effectively teach, organize discussion, ask questions, stimulate students' motivation and teach students in accordance with their aptitude; Scientific teaching organization can not only manage classroom activities and teaching time well, but also reflect the correctness and rationality of teachers' teaching behavior in the teaching process, the diversity and flexibility of teachers' teaching strategies, as well as the appropriateness and usefulness of teaching content. From the perspective of students' learning effect, it reflects that students can obtain specific progress and development after teachers' travel teaching. Whether there is a corresponding learning effect for students after teaching does not mean that the teacher is not serious about teaching or has not finished teaching content, but whether the students are good at learning or have learned something. If the teacher works hard and the students fail to learn anything, the teacher will not be able to learn anything. So even if teachers teach hard, their teaching can only be regarded as a kind of ineffective teaching or inefficient teaching. Therefore, the key to effective teaching lies in the unity of teachers' teaching efficiency and students' learning efficiency. In short, effective teaching means that teachers teach well, students learn well, teachers teach efficiently and students learn effectively.

\section{Analysis on the Current Situation of Effective Teaching of Basketball Course for Physical Education Majors in Colleges and Universities}

In order to better understand the basic problems existing in the effective teaching of basketball general course of physical education major in Colleges and universities in China, through searching for literature, telephone and interview experts, listening to and commenting on the course in and out of colleges and universities, combined with the author's 15 years' working experience in basketball general course of physical education major in Colleges and universities, At present, there are three main problems in the effective teaching of basketball course of physical education major in Colleges and Universities: cognitive bias, ignoring the effectiveness of the teaching process, and alienation of the effective teaching effect orientation.

\subsection{Cognitive Bias of Effective Teaching}

The core idea of effective teaching is to care about the efficiency of classroom teaching. However, in the teaching of basketball general course of physical education major in
Colleges and universities, many teachers have obvious cognitive bias to effective teaching and fail to correctly understand the idea of effective teaching. As a result, many teachers believe that the teaching that students can listen to the class seriously and obey the teacher's arrangement and practice well is good teaching. It is effective teaching, which has cognitive bias in thought and tends to be far away from or deviate from effective teaching in teaching behavior. First of all, it pays too much attention to the leading role of teachers. Due to the cognitive bias of effective teaching, many teachers overemphasize the status and role of teachers in teaching, and think that teachers are the dominant in classroom teaching, resulting in the whole classroom teaching is controlled by teachers, resulting in the teaching situation of teachers' one speech. It is true that many teachers pay too much attention to their leading role in the teaching of basketball general course, resulting in the situation of teachers' one word teaching. Most of the time when teachers teach is their own leading explanation, which takes up most of the time of the whole class. They overuse the explanation and neglect that basketball general course is a course with skills. In order to better learn and consolidate the technical movements and tactical cooperation, and to better improve the effectiveness of teaching, skills courses should be less intensive and more practice. Secondly, the main role of students is ignored. At present, due to the cognitive bias of effective teaching, the main role of students is ignored in the teaching of basketball general course of physical education major in Colleges and universities, and students' learning enthusiasm and subjective initiative are not mobilized. On the one hand, it is mainly due to the lack of communication with students and interaction with students. In classroom teaching, students are too strict to obey the teacher's arrangement. Students are not easy to ask questions when they encounter problems in class. Even if students ask questions, the tense of teachers' answers is not very good. As a result, many students do not dare to consult the teacher even if they encounter problems in the process of practice. This kind of failure to fully mobilize the students' learning enthusiasm and subjective initiative in the teaching process is bound to affect the effectiveness of classroom teaching. On the other hand, it mainly ignores the requirements of repeated learning. College physical education professional basketball course is a skill course, students' mastery of basketball skills needs a long-term repeated process, relying on classroom teaching is extremely limited time, it is difficult to learn the basic skills and tactics of basketball, extra-curricular time must also strengthen practice to better grasp these basic skills and tactics. Therefore, it is necessary to require students to establish the idea of repeated learning in order to receive good learning effect. Unfortunately, some teachers do not require students to learn basketball skills repeatedly in teaching, which affects the effective teaching.

\subsection{Ignoring the Effectiveness of Teaching Process}

There are some teachers who ignore the effectiveness of the teaching process in the teaching of basketball general course of physical education major in Colleges and universities. First, ignore the effective preparation process before class. The effectiveness of classroom teaching largely depends on whether the class can be prepared before class, but in the teaching of basketball general course, some teachers fail to 
prepare the class before class. Firstly, the teaching objectives of lesson preparation before class are too high, too many and too empty, which are not concise and clear enough. They fail to formulate clear and scientific teaching objectives, and they also fail to establish good teaching focus around the teaching objectives; On the other hand, the pre class preparation fails to grasp the "measurement" of teaching content, effectively grasp the amount of technical and tactical exercises required by students' classroom teaching, scientifically arrange and match the density and intensity of technical and tactical exercises according to teaching principles, and reasonably organize and grasp the degree of teaching content; Third, pre class preparation failed to give priority to optimizing teaching methods, failed to select appropriate teaching methods in combination with actual teaching content, textbook characteristics and students' situation, and failed to improve effective teaching by optimizing teaching methods [11]. Secondly, the effective organization of classroom is ignored. Effective classroom organization is bound to improve effective teaching, but in the teaching of basketball general course, some teachers fail to organize classroom teaching effectively. On the one hand, the explanation of skills and tactics is not accurate and concise. Teachers explain some things that have nothing to do with the practice content or have little to do with it, and fail to explain the concepts of skills and tactics The main points and principles of technical movements should be explained clearly, and it is bound to occupy students' effective learning time to explain them endlessly; On the other hand, the teaching organization process is too rigid, and the effective practice time of teaching is not well grasped. For example, when the professor is walking, there are many empty places to use, but only one side of the basketball is used for teaching. As a result, the students form a long line to practice in turn, and they can not practice several layups after a class. This kind of teaching which does not grasp the effective practice time will cause a serious waste of students' effective practice time; In addition, the basic principle of differential treatment is not followed, and the differences of students' gender, foundation and learning acceptance ability are not taken into account in the teaching process. This kind of unified teaching without differential treatment of students will inevitably affect the effective teaching. Third, ignore the effective practice after class. It is difficult for students to master a technique or tactics through the stages of generalization and differentiation of techniques and tactics. Therefore, it is necessary for teachers to put forward to students that they should make full use of all possible time after class to practice techniques and tactics so as to be able to master tactics. But in the teaching of basketball general course, some teachers fail to emphasize the importance of after class practice to students, which affects the effective teaching.

\subsection{Alienation of Effective Teaching Orientation}

In the teaching of basketball general course, only by following the basic rules and principles of teaching, can we effectively improve the effective teaching and gain better teaching effect. However, in reality, some teachers deviate from the teaching principle due to the excessive pursuit of the maximization of teaching effect, leading to the alienation of effective teaching orientation. Basketball teaching is divided into two parts: basic skills teaching and basic theory teaching. Once the teaching effect is overemphasized in the teaching process, both basic skills teaching and basic theory teaching may lead to the alienation of effective teaching. On the one hand, the alienation of the effective teaching orientation of basketball basic skills lies in the fact that many teaching goals are effective teaching or good teaching effect, so we blindly pursue too many teaching goals in classroom teaching. However, due to too many teaching goals, we can not effectively complete them one by one, which deviates from the original effective teaching goals, leading to the alienation of effective teaching goals. On the other hand, he thinks that more teaching content means effective teaching or better teaching effect. Therefore, he arranges teaching content as much as possible in classroom teaching, neglecting that basketball skills are a step-by-step practice and mastery process. If a student seldom plays basketball at ordinary times, he has a poor foundation, It is impossible to master a new basketball technique in a class, such as one handed shoulder shooting technique in situ. In the teaching, due to too much teaching content, students can not complete the teaching task according to the technical specifications, which deviates from the original arrangement of teaching content, thus leading to the alienation of effective teaching content [12]. The above-mentioned basic skills teaching of basketball, which is eager for quick success and instant benefit and excessively pursues the maximization of teaching effect, may violate the law of education and lead to the alienation of effective teaching. The alienation of teaching orientation of basketball basic theory mainly lies in instilling teaching method. In the teaching of basketball basic theory, some teachers pursue the effective teaching method of maximizing the teaching efficiency. This teaching method regards the teaching activities as a storage behavior, and thinks that the more storage, the higher the efficiency. At the same time, it advocates that the students should be taught as much knowledge as possible in unit time, but this teaching method ignores the guidance, teaching and learning The role of inspiration in the teaching of basketball theoretical knowledge makes students easily lose their subjective initiative, judgment consciousness and reflective ability in the teaching process. It also fails to take into account students' interest in learning basketball theoretical knowledge and their individual differences. It is easy to destroy students' interest in learning and even kill students' learning ability, Therefore, this kind of teaching method is easy to be alienated into indoctrination teaching method.

\section{Strategies to Improve the Effective Teaching of Basketball Course for Physical Education Majors in Colleges and Universities}

\subsection{Correct Understanding of Effective Teaching}

To put it simply, effective teaching is to teach effectively and learn effectively, that is to say, teachers teach well and students learn well. Only by conscientiously implementing the effective teaching concept, correctly understanding the effective teaching in thought and strictly implementing the effective teaching in teaching behavior, can teachers really improve the effective teaching of basketball general course of physical education major in Colleges and universities. 
Therefore, teachers should do the following in the teaching process: first, establish a clear teaching goal. Whether it is the teaching of basketball basic skills or the teaching of basketball basic theory, teachers should make preparations in advance, establish clear teaching objectives in line with the teaching law, and make overall arrangements for the choice of teaching contents, the choice of teaching activities, the choice of teaching methods, and the grasp of teaching difficulties under the guidance of clear teaching objectives, Through the clear teaching objectives to guide teachers to carry out classroom teaching efficiently and orderly, so as to effectively improve the effective teaching of basketball teaching. Second, we should fully mobilize students' subjective initiative. The improvement of students' mastery of knowledge and application ability is an important indicator to measure the effectiveness of teaching activities. The improvement of students' mastery of knowledge and application ability largely depends on whether students' subjective initiative can be mobilized. Teachers should pay attention to students' learning enthusiasm and initiative in the teaching process. Only by fully mobilizing students' subjective initiative in learning can we receive good and effective teaching effect. Third, we should cultivate students' habit of thinking. Thinking is an activity to explore and discover the internal essential relationship and regularity of things, and it is an advanced stage in the process of cognition. The mode of thinking can be divided into logical thinking, image thinking, insight thinking and so on. Different forms of thinking have different effects on learning, but can have a positive impact on the learning effect. For example, logical thinking has an important impact on students' learning of basketball theoretical knowledge, image thinking is conducive to students' mastery of technical movements, and insight thinking is conducive to stimulating students' tactical cooperation. Therefore, whether the basic skills of basketball teaching or the basic theory of basketball teaching, teachers should help students develop good thinking habits, form a flexible way of thinking, and improve effective teaching by cultivating students' thinking habits.

\subsection{Focus on Effective Teaching Process}

Effective teaching effect is closely related to whether the effective teaching practice process is scientific and reasonable. Only when the teaching practice process is scientific and reasonable, can more effective teaching effect be produced. In other words, effective teaching emphasizes the legitimacy of the teaching process and the rationality of teaching means. Therefore, it is necessary to pay attention to the effective teaching process in basketball teaching. First of all, the construction of process teaching evaluation system. Process teaching evaluation has the role of identification and recognition for teachers' teaching process work. If teachers can not get effective teaching evaluation and recognition for what students do in the teaching process, then teachers can not take the teaching process seriously, or even perfunctory teaching in the teaching process, and it is difficult to receive the expected teaching effect. Therefore, it is necessary to build a process teaching evaluation system, through the construction of scientific and reasonable process teaching evaluation system, to ensure that teachers in the teaching process of all reasonable and legitimate teaching are recognized, in order to encourage teachers to improve effective teaching. Secondly, we should pay attention to improving students' learning process. One is to encourage students to study in a variety of ways. Different skills and knowledge of basketball general course need to adopt different learning methods. Finding appropriate learning methods can effectively promote the learning effect. Therefore, teachers should encourage students to use a variety of methods to learn, whether it is the teaching of basic basketball skills or basic basketball theory. Using a variety of methods and adaptive use can effectively promote students to better grasp the basic skills and basic knowledge of basketball. The second is to encourage students to study hard by praising and recognizing them. In the process of teaching, students can be praised by direct oral language to improve their learning interest and enthusiasm. For example, in the teaching of basketball skills, when the learning skills are well completed, the students' learning interest can be effectively stimulated by giving praise by direct language. This kind of language praise can also play a certain role in motivating other students. Therefore, in the teaching process of basketball general course, we can praise and recognize students, so that students can better stimulate students' interest in learning after successful experience to improve effective teaching.

\subsection{Establish Effective Teaching Goal Orientation}

First of all, we should pay attention to teachers' ethics. It is meaningful for teachers to teach well and efficiently in advance under the supervision of ethics. Therefore, in the effective teaching of basketball general course, teachers' ethics should be paid attention to. Teachers' public morality and private morality should be paid attention to. Only in this way can basketball general course teaching be regarded as meaningful and effective teaching. Therefore, teachers should love students from the bottom of their hearts, treat every student equally in the process of basketball teaching, treat all students equally, and let students really feel the love from the bottom of their hearts, Make the students feel sorry for the teacher if they don't study basketball knowledge and practice basic skills; At the same time, teachers should also strengthen the communication with students. Teachers should sincerely communicate and dialogue with students in the teaching process of basketball general course, so that the whole classroom teaching can become a sincere communication activity between teachers and students, so as to promote students' learning enthusiasm and interest. Secondly, take the equal development of students personality as the goal of teaching development. In the ethical orientation, taking the equal development of students' personality as the goal of basketball teaching is one of the important measures of effective teaching. Students, as the objects of education, have their own unique personality and personality, and should be treated equally and protected and respected in the process of basketball teaching. Only when teachers pay attention to the equal development of students' personalities, can they pay more attention to students' personalities and unique values in the process of teaching activities of basketball general course, give appropriate education to students' personality development, make students' personalities develop correctly and appropriately, and effectively reflect the real value of effective teaching [13]. 


\section{References}

[1] Rajendra Kunwar. Math Mania: implications, issues and approaches for effective teaching of mathematics in basic education in Nepal [J]. Journal of Research in Vocational Education, 2020, 2(9): 5-10.

[2] Hans Teke. Making ethics teaching more effective with a three step model[J]. International Journal of Ethics Education, 2020, 3(8): 1-14.

[3] Wei Hong, Shen Jiliang. Analysis on the characteristics of effective teaching of university teachers [J]. Journal of Southwest Normal University (Humanities and Social Sciences Edition), 2002, 28(03): 33-36.

[4] Wang Xi. Research on classroom behavior differences between effective teaching and inefficient Teaching [J]. Educational Theory and Practice, 2000, 20(09): 50-53.

[5] Wang Shuwei. Research on the effectiveness of physical education classroom teaching in senior high schools in Lanzhou [D]. Northwest Normal University, 2020.

[6] C Kyriacou. Effective teaching in school [M]. Basil Balackwell, Ltd, 1986, 9.

[7] R Ballentyne et al. Researching university teaching in Australia [J]. Studies in Higher Education, 1999, 24(2): 237-257.

[8] Zhang Lu. Rethinking effective teaching [J]. Educational Theory and Practice, 2002, (3): 48-50.

[9] Yao Limin. Research on the characteristics of effective teaching in universities $[\mathrm{J}]$. Modern University Education, 2001, (4): 42-44.

[10] Li Shihai. Strategies for improving the effectiveness of School Physical Education [J]. Chinese Journal of Education, 2017, (S1): 96-97.

[11] Zeng Yushan, Yang Xiudi, Wang Hong, Wang Jian. The lack, construction and implementation of effective standards of Physical Education [J]. Journal of Shandong Institute of Physical Education, 2020, 36(05): 16-22.

[12] Zhang Yubao. From "plan" to "national standard": evolution, characteristics and enlightenment of curriculum setting of physical education specialty [J]. Journal of Physical Education, 2020, 27(01): 93-98.

[13] Chen Lingling. Types, problems and improvement suggestions of effective teaching $[\mathrm{J}]$. Teaching and Management, 2019, (06): 4-7.

\section{Author Profile}

Songhe Xin, (1973-), male, $\mathrm{PhD}$, associate professor. Research in physical education. 